\title{
Correction to: Surgeon experience with dynamic intraligamentary stabilization does not influence risk of failure
}

\author{
Philipp Henle ${ }^{1} \cdot$ Kathrin S. Bieri ${ }^{2}$. Janosch Haeberli ${ }^{1}$ Nele Arnout ${ }^{3} \cdot$ Jan Victor $^{3} \cdot$ Mirco Herbort $^{4}$. \\ Clemens Koesters ${ }^{4}$. Stefan Eggli ${ }^{1}$
}

Published online: 25 August 2018

(c) European Society of Sports Traumatology, Knee Surgery, Arthroscopy (ESSKA) 2018

\section{Correction to: \\ Knee Surgery, Sports Traumatology, Arthroscopy https://doi.org/10.1007/s00167-018-4847-0}

The original version of this article unfortunately contains mistake in Table 4. The $p$ value of the univariable Age and
Tegner score and the OR (Multivariable) value of Injury to surgery have been corrected.

The corrected Table 4 is given below:
Table 4 Uni- and multi-variable regression analysis of factors associated with revision ACL surgery

\begin{tabular}{|c|c|c|c|c|c|c|}
\hline \multirow[t]{2}{*}{ Variable } & \multicolumn{3}{|c|}{ Univariable } & \multicolumn{3}{|c|}{ Multivariable $(n=96)$} \\
\hline & OR & $95 \%$ CI & $p$ value & OR & $95 \% \mathrm{CI}$ & $p$ value \\
\hline \multicolumn{7}{|l|}{ Categoric } \\
\hline Designer surgeons & 1.48 & $(0.42-6.01)$ & n.s & 2.25 & $(0.45-14.25)$ & n.s \\
\hline Male gender & 2.60 & $(0.70-12.51)$ & n.s & 2.24 & $(0.40-16.01)$ & n.s \\
\hline Proximal tear & 0.27 & $(0.07-1.18)$ & n.s & 0.29 & $(0.05-1.69)$ & n.s \\
\hline Adjuvant procedure & 1.19 & $(0.32-4.25)$ & n.s & 1.23 & $(0.24-6.01)$ & n.s \\
\hline \multicolumn{7}{|l|}{ Continuous } \\
\hline Age (years) & 0.88 & $(0.78-0.97)$ & 0.020 & 0.92 & $(0.80-1.02)$ & n.s \\
\hline Tegner score $(0-10)$ & 1.55 & $(1.05-2.38)$ & 0.032 & 1.45 & $(0.87-2.62)$ & n.s \\
\hline Injury to surgery (days) & 0.97 & $(0.84-1.11)$ & n.s & 1.00 & $(0.85-1.18)$ & n.s \\
\hline
\end{tabular}

The original article can be found online at https://doi.org/10.1007/ s00167-018-4847-0.

Kathrin S. Bieri

kathrin.bieri@ispm.unibe.ch

1 Department of Knee Surgery and Sports Traumatology, Sonnenhof Orthopaedic Center, Bern, Switzerland

2 Swiss RDL, Institute of Social and Preventive Medicine, University of Bern, Finkenhubelweg 11, 3012 Bern, Switzerland

3 Ghent University Hospital, Ghent, Belgium

4 University Hospital Muenster, Westphalian-Wilhelms University, Muenster, Germany 